\title{
Unpacking the policy landscape for implementing an Information Communication Technology (ICT) based in Human Resources Management tool in government health sector in Bangladesh: Findings from a policy review
}

Dipika Shankar Bhattacharyya ( $\Delta$ dipikashankar@gmail.com )

International Centre for Diarrhoeal Disease Research

\section{Goutam Kumar Dutta}

International Centre for Diarrhoeal Disease Research

\section{Iffat Nowrin}

International Centre for Diarrhoeal Disease Research

\section{Sohana Shafique}

International Centre for Diarrhoeal Disease Research

Md. Zahidul Islam

Directorate General of Health Services

B. M. Riazul Islam

Directorate General of Health Services

lqbal Anwar

International Centre for Diarrhoeal Disease Research

\section{Research Article}

Keywords: Health Policy, Human Resources for Health, Information Communication and Technology, Policy Review, Bangladesh

Posted Date: February 11th, 2021

DOI: https://doi.org/10.21203/rs.3.rs-156412/v1

License: (c) (i) This work is licensed under a Creative Commons Attribution 4.0 International License. Read Full License 


\section{Abstract}

Introduction: In Bangladesh, to address the challenges of ensuring adequate human resources for health $(\mathrm{HRH})$, the government began implementing a digital tool for $\mathrm{HRH}$ management in 2017. However, evidence suggests institutionalizing such tools in low-and-middle-income-countries are impeded by policy aspects like implementation strategy and poor regulatory framework. We aimed to explore factors in the current policy landscape that might facilitate and challenge the implementation of the tool in Bangladesh.

Methods: We conducted a review of policies related to ICT implementation and human resources management in health sector in Bangladesh using qualitative content analysis method. Twelve policies have been identified and comprehensive reading was done to ascertain common themes and patterns. $A$ document analysis matrix was developed to synthesize and help interpreting the findings.

Results: Regarding facilitators, strong upstream level commitments were reflected in the content of policies in terms of setting out specific objectives, targets, timeline, and budget allocation. However, lack of explicit monitoring strategy and extent of stakeholders' engagement was not well-defined, ultimately create chances for making downstream implementation disjointed. In addition, effective coordination among stakeholders and different HRH and ICT policies could be strengthened.

Discussion: Findings support the current discourse that national commitment plays a vital role in integration of ICTs in health services. However, well-defined monitoring strategy and inter-ministry and intra-ministry policy coordination is crucial.

\section{Introduction}

Human Resources for Health ( $\mathrm{HRH})$ is regarded as the heart of any health system (1) that plays a pivotal role in ensuring provision of high quality health care services and thus improving health outcome of the population (2). The recognition that population health outcome is by and large, related to number, quality, and equitable distribution of $\mathrm{HRH}$, has drawn policy interest in recent years resulting in enhanced advocacy, investment and action at global, regional and national level (3-5). There have been several international calls to strengthen health systems for recording and updating health workers numbers, deployment and movement (5). However, there is lack of organized single data-source in the context of Low-and-Middle-Income-Countries (LMICs) that captures the various dynamics of HRH stocks and flows for management decision support. In general, HRH information can be gleaned from several databases such as national censuses, labor force and employment surveys, health facility surveys and administrative databases of the public and private sector organizations although many of them are not designed for the specific purpose of $\mathrm{HRH}$ planning and management.

Dussault et al. (2003) has mentioned that lack of evidence-base in HRH policy making may cause imbalance in production, inappropriate skill-mix, and inequitable distribution leaving many rural and hardto-reach areas underserved (3). These crises are particularly more evident in LMICs (6) where health 
systems governance and stewardship is poor. In Bangladesh, HRH management faces many challenges and discussed in the health system and policy discourse over a long period of time (7). The World Health Organization (WHO) has identified Bangladesh as one of the country with 'severe health workforce shortage'. Moreover, the existing HRH is inequitably distributed- huddled disproportionately in urban areas $(8,9)$. Therefore, efficient HRH planning and management is one of the priority issues in Bangladesh to achieve universal health coverage (UHC) and health related targets of the SDGs $(10,11)$.

In order to improve HRH management, developing a comprehensive system for collecting, organizing and disseminating HRH information - referred to as 'human resource information system' (HRIS) is the vital first step $(1,12)$. This was strongly emphasized in the first global forum for Human Resource for Health (HRH), in Kampala, in 2008 (13). A functional model HRIS uses standardized methods for capturing and analyzing data to store and analyze updated, correct and complete information on health workforce. In addition, this helps the policy makers to create a solid evidence-base by linking the health workforce data with other health indicators, e.g. disease burden and service utilization. The usefulness of such coordinated and standardized health workforce information system have been highlighted in several international and regional calls.(13-19).

In line with these Global recommendations, Bangladesh has started implementing an internet-based ICT tool - known as Human Resource Information System (HRIS) - in 2017 to improve human resource management in the government health sector in Bangladesh. Anchored within the Management Information System (MIS) of the Directorate General of Health Services (DGHS), the HRIS tool is for creating a robust central platform that incorporate and process HRH data of government health system from all over the country (20).

However, global evidence suggests that institutionalizing any ICT tool in the healthcare organizations in LMICs resource-poor countries are impeded by multiple factors, which include policy level regulatory issues and context-specific bottlenecks at the implementation level $(5,21,22)$. It is important to understand to what extent the existing policies are aligned with the implementation of HRIS in Bangladesh, and whether there is any need to change the existing policies for improving the efficiency, effectiveness and sustainability of the HRIS tool. In this context we conducted an exploratory study to explore the policy level factors that supported or constrained the implementation of the ICT-based HRIS tool for improving $\mathrm{HRH}$ management in Bangladesh.

\section{Methods}

\section{Data Source:}

We undertook a 'policy-analysis' on 'ICT implementation and human resources management' in the health sector in Bangladesh using qualitative 'content analysis' research method (23). All national level policy documents with specific components on HRH or ICT, and having a potential to impact 'integrating ICTs in the HRH management in Bangladesh' were included in the review. In addition, policies not directly linked to $\mathrm{HRH}$ or ICT, but have overarching impact on the overall HRH policy and management were considered. 
Policies that have HRH or ICT issues but do not converge each-other were not included. All recent policies, strategies, guidelines, programme implementation plans, and budgets of the MOHFW were accessed either from ministry websites or through personal communication with relevant stakeholders. In total, 12 National level policies and strategies that focused on integration of ICT in HRH Management in Bangladesh were included in the review (Table 1).

Table 1: List of policies reviewed

\begin{tabular}{|l|l|l|l|}
\hline $\begin{array}{l}\text { SL } \\
\text { No. }\end{array}$ & Name of policies & Implementer & $\begin{array}{l}\text { Enacted } \\
\text { year }\end{array}$ \\
\hline 1 & The National ICT Policy & MoSICT & 2009 \\
\hline 2 & The National Health Policy & MoHFW & 2011 \\
\hline 3 & Program Implementation Plan (PIP) & MoHFW & 2011 - \\
\hline 4 & Bangladesh Health Workforce Strategy & MoHFW & 16 \\
\hline 5 & Program Implementation Plan (PIP) & MoHFW & 2015 \\
\hline 6 & The National ICT Policy & & $2017-$ \\
\hline 7 & Health Care Financing Strategy & MoSICT & 2022 \\
\hline 8 & $\begin{array}{l}\text { Human Resources For Health Country } \\
\text { Profile Bangladesh }\end{array}$ & $\begin{array}{l}\text { Human } \\
\text { Unit, MoHFW }\end{array}$ & 2018 \\
\hline 9 & Journey to SDGs for health & DGHS, MoHFW & 2032 \\
\hline 10 & Transfer Rules of 3-4th Class Workers & MoPA & 2013 \\
\hline 11 & $\begin{array}{l}\text { Intra-department Transfer Rules of 9-7th } \\
\text { Grade and Non-cadre 2017 }\end{array}$ & MoHFW & 2017 \\
\hline 12 & Bangladesh Gazette for Non-medical Person & MoPA & 2017 \\
\hline
\end{tabular}

All the policies included in the review were formulated between 2009 and 2018 except one which was enacted in 1986 (24). Among them six policies focused on the use of ICT in HRH management others have relevance or implications for introducing ICT in HRH management. The identification of these policies was through detail discussions with relevant stakeholders working on $\mathrm{HRH}$ issues in the public or in the private sector in Bangladesh.

\section{Data Extraction Process:}


Once the documents have been finalized the authors undertook a comprehensive and organized reading of the texts in the policy documents in order to identify codes and patterns $(23,25)$. All the included policies were read and re-read line by line to achieve full comprehension and to refine the findings. The selected lines were coded and sorted into themes as per the study objectives. We used Atlas.ti 7.5 electronically for coding the texts, store the findings, and organize the systematic readings. A document analysis matrix was developed, where the first column of the matrix represented name of policy/strategy with their enactment year, the second column to write name of the ministry that formulated the policy, the third column was for incorporating the facilitating factors and the fourth column was for writing the implementation challenges. Finally, the fifth column was for any remarks of the reviewer including any important background information on the policy. However, the third and fourth column has been subdivided into three parts to extract policy-content on the implementation strategy, budgetary allocation and stakeholders engagement. From all the selected policies information were extracted to fill the data display matrix.

\section{Data Analysis:}

For data analysis, the information from data display matrix described above was synthesized. The study investigators themselves conducted the document review and detailed analysis. It is worth mentioning that many of the policy documents were in Bangla and all the authors were fluent in both Bangla and English to extract, interpret and synthesize the information. In this regard, the key themes from all the policies were first identified and then the authors conducted further analysis through synthesizing this information to explore and understand policy level factors that supported or constrained the implementation of the HRIS tool for improving HRH management in Bangladesh context. The policy review was guided by the "Policy Analysis Framework" proposed by Collins (2005) (26) following eight steps: 1) define the context; 2) state the problem; 3) search for evidence; 4) consider different policy options; 5) project the outcomes; 6) apply evaluative criteria; 7) weigh the outcomes; and 8) make the decision. We have covered the steps 1-3 in the introductory section of this paper. In order to present the findings of steps 4-8, the authors have broadly categorized the result in two broad themes; i) policy level facilitators to integrate ICTs in HRH ii) Lacunae in policy and the scope for further strengthening.

\section{Results}

\section{- Policy level facilitators to integrate ICTs in HRH}

The key issues identified as the facilitating factors are as follows.

\section{i) Upstream level decisions for integrating ICT and health}

Strong upstream level commitments have been found in the policy landscape regarding the integration of ICT across all government departments including health. The government manifesto of "Digital Bangladesh", formulated in 2009, advocates for ensuring an ICT-based society where all possible 
activities of the government, non-government and semi-government organizations will be performed using ICT network for ensuring equitable and comprehensive development by 2021 (27). Placing this "Vision 2021 Agenda" as a guiding principle of the government, all ministries of the government of Bangladesh began to thrive using digital platforms for providing need-based high quality services for all citizens of the country.

In addition, the Government of Bangladesh expressed commitment to achieve Universal Health Coverage (UHC) by 2032. With this aim, the 'health care financing strategy' was formulated by the Ministry of Health and Family Welfare (MOHFW) in 2012, that clearly acknowledges that, along with other factors, human resource development as well as proper utilization of ICT is imperative for achieving UHC goals (28). Bangladesh has signed the United Nations Sustainable Development Goals (SDGs), which obligates the Government of Bangladesh to make stronger investments for improving HRH management. All these upstream policy level commitments could create a conducive environment to integrate ICT for health systems strengthening which is evident in recent advancement in MOHFW - such as introduction of online DHIS2, Open MRS, HRIS etc. for ensuring 'measurement and accountability' and 'data for decision making' in the public sector health care delivery system.

\section{ii) Commitments for ICT based HRM}

The upstream level commitments have been reflected in the content of relevant policies and strategies of the Ministry of Health and Family Welfare (MOHFW). The National ICT Policy 2009 formulated by the Ministry of Science and Information \& Communication Technology (MoSICT) is one of the prime examples. This policy was formulated to function as "binding guide" for adopting ICTs by all other ministries of the government to improve efficiency and effectiveness of government interventions. Giving emphasis on health system, the national ICT policy provided strategic guidance to improve the health care delivery system through introduction of e- and m-health. In addition, under the strategic theme 7.1, the ICT policy recommends developing, updating and using a comprehensive national database for all $\mathrm{HRH}$ including, doctors, nurses, paramedics as well as the alternative medical practitioners in the country. The policy particularly recommends that this comprehensive and dynamic database will be used for all kinds of $\mathrm{HRH}$ management activities including recruitment, posting, transfer, retention and retirement. Importantly, creation of this database was taken as priority short term task, mentioning as "need of the hour", which was supposed to be implemented within 18 months of policy formulation. Therefore, the national ICT policy was the first impetus for building and using an ICT-based tool for improving HRH management in the government sector (29).

One of the main goals of The National Health Policy (2011) was to ensure the best utilization of ICT tool for improving overall health systems performance. Although there is no specific content in National Health Policy for integrating ICT in HRH management, its strategy\#13 has clear and elaborate recommendations for establishing an integrated management information system using computer network for planning, implementation and monitoring of all health programmes in the public sector (30). 
The Program Implementation Plan (PIP) of the "4th Health, Population and Nutrition Sector Development Programme (HPNSDP) 2011-16" is the first policy document in the health sector that took specific decisions to provide accurate and up-to-date HRH information to policy makers and all relevant stakeholders for better HRH planning and management. The operation plan (OP) on HRM of the 4th HPNSDP identified problems for not having a central information system on $\mathrm{HRH}$ and thus endorsed specific decision for establishing ICT based HRH information system for ensuring real-time data for management decision support and planning. In this policy, specific target was set to establish a central HRIS within 2014 and to utilize it for HRH management by mid-2016 (31). More importantly, there was clear recommendations for updating National Health Workforce Strategy for promoting evidence-based $\mathrm{HRH}$ planning and management. Based on this recommendation, 'The Health Workforce Strategy 2015' was formulated by MOHFW, in which "Health Workforce Information System (HRIS)" was taken as one of the five main thematic areas. Under HRIS thematic area, the major commitment was to establish a comprehensive central health workforce information system to promote evidence-based decision-making in HRH management (32). This was further enforced in the PIP of next health sector program 'the Health Nutrition, and Population Sector Program (2017-2022) which has taken three major activities to be accomplished by 2022-i) Establishing one central HRIS that is linked to all agencies; ii) Capacity building from central to periphery level for institutionalization of the online HRIS and iii) Using HRIS data for evidence- based planning and decision-making, and all these activities are to be completed by 2022 (33). The PIP of HPNSP (2017-2021), has identified the DGHS as the first initiator and other departments within MOHFW have been advised to introduce HRIS for better HRH management.

\section{iii) Budget allocation}

The PIPs of 3rd and 4th health sector program has allocated adequate budget for establishing and utilizing comprehensive ICT-based HRH management tool. In PIP (2011-16), a total of 14747.00 lakhs (USD 17.393 million) was allocated for development and management of HRH. In this budget, specifically 670.00 lakhs (USD 0.790 million) was allotted for developing Human Resources Information System (HRIS) and automation of HR management process (posting, training and transfer) (31). In the next PIP (2017-21) a total of 9982.47 lakhs (USD 11.770 million) was allocated for overall improvement of HRH management. From this amount, 2193.00 lakhs (USD 2.587 million) was allocated for implementing and monitoring HRIS tool centrally. It is important to mention that, this policy mentioned the explicit allocation strategy of the budget over the period of 5 years, e.g. 62.00 lakhs (USD 0.073 million) was allotted for establishing one central HRIS that is linked to all agencies within MOHFW; 61.00 lakhs (USD 0.072 million) for establishing monitoring framework for implementation of Health Workforce Action Plan, 61.00 lakhs (USD 0.072 million) to ensure use of HRIS data for evidence-based planning and decision making, 1570.00 lakhs (USD 1.852 million) for research/ survey/ study and 439.00 lakhs (USD 0.518 million) for seminar/ conference/ training required for implementation of HWF (33).

\section{- Lacunae in policy and scope of strengthening}

i) Stakeholder engagement: 
There are specific recommendations across the policies to engage different stakeholders for implementing the HRIS. In general, the government agencies, semi-government institutes and in some cases private sector organizations were identified as stakeholders to implement the HR related policies. However, there was no specific declaration about the role of the implementing bodies and there was limited information about the extent of engagement of other (than government) stakeholders. For example, according to the National ICT policy 2009, Bangladesh Computer Council or its successor organizations are identified as the implementing actors. But the specific role of each of the implementing bodies such as other ministries and departments were not explicitly mentioned in the policy. The policy also identified private sector as one of the primary actors to implement the $\mathrm{HRH}$ database (item\#218, under Objective\#7). However there is no clear role clarification on how the private sector players will be engaged in the planning and implementation process (29).

The 4th Health, Population and Nutrition Sector Programme (HPNSP 2011-2016) declared the importance of engaging multiple stakeholders in $\mathrm{HRH}$ management with their full involvement as per requirements. But there is no reflection about the scope of engagement multiple stakeholders for specific tasks. Similarly, 'Bangladesh Health Workforce Strategy - 2015' recommended some strategic intervention in short-term, mid-term and long-term for strengthening the health workforce information system. However, there is no budget attached with this strategy. In this regard, both government agencies and private sector actors were identified as key stakeholders. However, there is no clear guideline on how to integrate all these stakeholders for a comprehensive national database. Monitoring the private sector data of $\mathrm{HRH}$ has been identified as one of the major challenges in these policies.

ii) Implementation and Monitoring strategy

The 3rd HPNSDP (2011-16) recommended for developing and establishing a Central Human Resource Information System (CHRIS) encompassing all the directorates and departments of MOHFW by 2016. However, the subsequent 4th HNPSP (2017-22) mentioned that the HRH data was not made available in a single place from all over the country. There was no specific reason mentioned regarding how the establishment of a central HRIS for all directorates was impeded. This policy (PIP 2017-22) also mentioned that, in the initiative of establishing comprehensive HRIS under the 3rd sector programme, the ownership of MOHFW was not prominent. This is also reflected in the Logical Framework of the 4th PIP, as under the component-5 "Important Assumption" was taken as "Health Service Division of the MOHFW has control on CHRIS based at MIS department of DGHS". This indicates that while the DGHS has a well-developed HRIS for capturing their countrywide HRH, there was a lack of implementation plan of other agencies within MOHFW.

The Health Workforce Strategy 2015 and the two PIPs (2011-2016 and 2017-2022) mentioned a long term plan for an assessment of the implementation, monitoring and reviewing of the HRIS. However, the other policies and strategies lack such strategy to evaluate the appropriateness of the design of the tool as well as the coordination mechanism among stakeholders in the implementation 
process. The National ICT Policy did not provide any clear idea about the budgetary allocation for developing and using the database for HRH management. Similarly, the Bangladesh Health Workforce Strategy 2015 recommended a step-wise approach for establishing and using the HRIS, but the action plans was designed without any specific budget.

- iii) Coordination among policies:

All these national level policies related to use of ICT in the management HRH were formulated gradually one after another over last 10-12 years. However, there are certain gaps with regards to coordination among these policies. For example, the National ICT policy enacted in 2009 had component on 'update and database for management of human resources' to be implemented as a short term task (within 18 months of policy formulation). However, the progress or implementation status of that policy was not reflected in the subsequent MOHFW policies such as PIPs of 3rd and 4th Health Sector Programme $(31,33)$ or Health Workforce Strategy 2015 (32). Even it was not explicitly mentioned in those policy documents.

Apart from inter-ministries policy coordination, there were also gaps in intra-ministry policies. For example, the MOHFW policies for transfer-posting of the employees necessitate involvement of multiple authorities in different tiers of health system. For example, DGHS is responsible for doing transfer and posting of staff within grade 7-9 (34). Whereas, the transfer and posting of 3-4th class employee is done under the Establishment Ministry (24), by sub-national level authorities at districts and division. Involvement of multiple authorities was clearly mentioned in those two policies; but none of these policies mentioned about the implication of HRIS tool in managing the database of HRH. Even, the latest, 'Bangladesh Gazette 2018 for non-medical' did not mention about the implication of ICT database upon management of this group of $\mathrm{HRH}(24,34)$.

\section{Discussion}

The study findings suggest that higher level national policies of the ministry of health and family welfare, ministry of ICT, and ministry of science and technology with clear mandate and timeline for achieving each HRH goals facilitated the initiative of implementing the ICT tool for HRH management in the government health sector. The findings support the current knowledge-base that the process of health related policy formulation is largely influenced by the upstream level political priorities of the national government and international agendas $(35,36)$. The "Digital Bangladesh" agenda of the government has been translated into the perspective plan of 2021 which ultimately guided the relevant ministries to take policy initiatives for digital solutions. This finding resonates to recent studies that shows there are number of good policies and relevant initiatives to incorporate ICTs in the health sector in Bangladesh $(20,37)$. The latest survey of World Health Organization on digital health has also emphasized that wellarticulated national e-health policy is a necessary prerequisite for strengthening health system through applying appropriate ICT solution and initiative (38). For the integration of ICTs in HRH management, the importance of upstream level policy is evident from studies in other LMICs. For example, in Mozambique 
a strong commitment of national leadership was instrumental for building a robust human resources information system in the public sector (39). On the other hand, in Pakistan the implementation of such ICT tool in HRH was largely hampered due to inadequate input from national level policies (40).

The study has highlighted the importance of budgetary allocation for implementation of the ICT tool in improving $\mathrm{HRH}$ management. Establishing a functional HRIS is a complex and difficult task in resourcepoor settings since it involves series of inter-related and successive actions- e.g. data collection, entering, analyzing, reporting- by separate entities at different tiers of health systems (5). Therefore, for ensuring a sustainable mechanism-solution in $\mathrm{HRH}$ management, continual fund allocation from the government is a necessary prerequisite. In this regard, the current policy Bangladesh policy has provided necessary guidance and allocated sufficient financial resources for the installation and subsequent training on the tool for different health system actors. Ensuring allocation of budget for the implementation of ICT tool in $\mathrm{HRH}$ management has been reported from other countries. For example, in Tanzania, the issues of maintenance and proper use was integrated into the e-Health strategy of the ministry of health to ensure the availability of fund for development of sustainable HRH information system (41).

The study findings also emphasized that although the policies have identified the key stakeholders but there is a need to give attention on making stakeholders on-board with clear role clarification. This finding is congruent to a recent assessment of sector-wide approach in Bangladesh suggesting the planning process in the government ministry is inherently centralized, which hampers decentralization and poses very limited scope for inclusion of non-state sector stakeholders in the health policy process (42). Especially in terms of implementing ICT tool in Bangladesh health system, absence of stakeholders' motivation was discussed as one of the major barriers in other studies (43). One study demonstrated that in Bangladesh, the initiative of establishing a central database for all health workers within different directorates of MOHFW was not fully accomplished as targeted. Besides, incorporating HRH data from private sector organizations was also challenging. A similar situation prevails in other countries. For example, the WHO hosted a technical meeting to bring together the experiences and to initiate discussion on ways for promoting comprehensive country health workforce information (including private sector data). The meeting emphasized that during the process of establishing such systems, the central concern is not only organizing the scattered data in one place, but more importantly on bringing different stakeholders together on a single platform (14). Therefore, developing and sharing a framework of stakeholder engagement for establishing and maintaining the $\mathrm{HRH}$ information systems might be helpful for all stakeholders to come into consensus around the implementation.

Our review was directed towards exploring the extent to which the current policies can support the implementation of HRIS in Bangladesh. The finding suggests, HRIS implementation is largely influenced by the idea that it will help the policy makers to make evidence-based decision around HRH issues in Bangladesh. Study from Kenya suggests that, in addition to day-to-day decision making, the implementation of such tool has the potential to impact policies as data from the Kenyan Health Workforce Information System (KHWIS) helped government to formulate policy to extend the retirement age of nurses since there were more nurse retiring than the upcoming young nurses in the health system 
(44). Therefore, in Kenya it was evident that policy formulation and implementation of ICT tool in HRH is a two-way relationship. However, in our policy review we did not find any documentation regarding how the HRIS implementation influences the policy making in Bangladesh.

A growing number of implementation research findings suggest that regular monitoring and evaluation has a strategic role in improving the relevance, efficiency and effectiveness of policy decisions in the LMIC settings $(45,46)$. Therefore, monitoring and evaluation need to be integrated into the design of policy implementation so that poor enforcement or resource wastage can be avoided (46). The study finding revealed that in Bangladesh several policy documents were formulated with specific directives on setting out targets, timeline, and budget allocation for establishing HRIS. However, effective coordination among different health workforce policies needs to be reinforced. Besides, coordination needs to be strengthened within different directorates as well as between private sector actors for creating a comprehensive health workforce information system. This finding resembles with a recent NCD policy analysis in Bangladesh, that concludes that despite the availability of quite a good number of policies, significant coordinated attention is warranted to monitor how these policies can be effectively implemented in the health system (47). Many countries are also envisaging similar problems. This is because in the policy enactment process often the weak mechanisms for providing feedback to decision makers are often overlooked (48).

The limitation of this paper is that it is based only on the review of policies, therefore it does not reflect the bottlenecks in the context of field level implementation. It is also worth mentioning that the policy review is not a straightforward method since multiple theoretical and methodological assumptions exist on how the public policies can be investigated and understood (49). However, this paper presented an integrated view of policy landscape in Bangladesh regarding the implementation of an ICT-based HRH management tool in the government health sector. In addition to create a knowledge-base on the strengths of the existing policies, the findings from this review lay a foundation for policy makers to identify the options that need to be addressed in future policies. We recommend further qualitative research on the key facilitators and challenges of field level implementation of the tool in the context of Bangladesh health system.

\section{Conclusion}

The development of innovative technology brings new opportunities for health system strengthening. However, while the technology offers new hope, there are also associated challenges with regard to how to best fit the technology within the health system considering the country context. Therefore, in order to leverage the best outcome of digital technology in health, review of national policy and strategy will create evidence-base to better support innovation. From this context, the findings of this research showed that national commitment plays vital role in integration of ICTs in health services. However, well-defined monitoring strategy and inter-ministry and intra-ministry policy coordination for creating a conducive environment is crucial for its strengthened implementation. More research is needed for exploring field level issues. 


\section{List Of Abbreviations}

DGHS Directorate General of Health Services

DHIS2 District Health Information System 2

ERC Ethical Review Committee

HPNSDP Health Population Nutrition Service Delivery Program

HPNSP Health Population Nutrition Sector Program

HRM Human Resources Management

$\mathrm{HRH} \quad$ Human Resources for Health

HRIS Human Resource Information System

HWF Health Workforce Strategy

ICT Information Communication and Technology

IDI In-depth Interviews

KHWIS Kenya Health Workforce Information System

KII Key Informant Interviews

LMICs Low and Middle Income Countries

MIS Management Information System

MOPA Ministry of Public Administration

MOSICT Ministry of Science and Information \& Communication Technology

NCD Non Communicable Diseases

OP Operation Plan

PIP Program Implementation Plan

RRC Research Review Committee

SDGs Sustainable Development Goals

UHC Universal Health Coverage 


\section{Declarations}

\section{Ethics approval and consent to participate}

This study has been approved by the institutional review board of icddr,b ( www. icddrb. org). The process includes approval from the research review committee for a critical examination of technical competencies and approval from the ethical review committee (ERC) for an in-depth investigation of ethical issues related to the local context. Informed consent was obtained from all study participants for taking the qualitative interviews. All study activities were carried out in accordance with relevant guidelines and regulations.

\section{Consent for publication}

Not applicable.

\section{Availability of data and materials}

The datasets used and/or analysed during the current study are available from the corresponding author on reasonable request.

\section{Competing interests}

The authors declare that they have no competing interests

\section{Funding}

This work was supported by Swedish International Development Agency (SIDA). The sponsors had no role in conceptualizing, designing, or writing this manuscript.

\section{Authors' contributions}

DSB and IA conceptualized the study, DSB prepared the first draft of the manuscript. GKD and IN carried out policy review and was a major contributor to writing the manuscript. SS, MZI and BMRI revised the manuscript. IA reviewed critically for important intellectual content; DSB compile inputs from all other coauthors, revised the manuscript for submission. All authors reviewed the manuscript.

\section{Acknowledgements}

This research study was funded by Swedish International Development Agency (SIDA). icddr,b acknowledges with gratitude the commitment of SIDA to its research efforts. icddr,b is also grateful to the Governments of Bangladesh, Canada, Sweden and the UK for providing core/unrestricted support. 


\section{References}

1. Organization WH. Monitoring the building blocks of health systems: a handbook of indicators and their measurement strategies: World Health Organization; 2010.

2. George A, Scott K, Govender V, Organization WH. A health policy and systems research reader on human resources for health: World Health Organization; 2017.

3. Dussault G, Dubois C-AJHrfh. Human resources for health policies: a critical component in health policies. 2003;1(1):1.

4. Rigoli F, Dussault GJHrfh. The interface between health sector reform and human resources in health. 2003;1(1):9.

5. Riley PL, Zuber A, Vindigni SM, Gupta N, Verani AR, Sunderland NL, et al. Information systems on human resources for health: a global review. 2012;10(1):7.

6. Dussault G, Franceschini MCJHrfh. Not enough there, too many here: understanding geographical imbalances in the distribution of the health workforce. 2006;4(1):1-16.

7. Organization WH. Bangladesh health system review: Manila: WHO Regional Office for the Western Pacific; 2015.

8. Management Information System D, Bangladesh. Health Bulletin 2017. Director General of Health Services; 2017.

9. Ahmed SM, Hossain MA, RajaChowdhury AM, Bhuiya AUJHrfh. The health workforce crisis in Bangladesh: shortage, inappropriate skill-mix and inequitable distribution. 2011;9(1):3.

10. Organization WH. More health workers needed for universal health coverage. WHO Bulletin. 2018.

11. Adams AM, Ahmed T, El Arifeen S, Evans TG, Huda T, Reichenbach LJTL. Innovation for universal health coverage in Bangladesh: a call to action. 2013;382(9910):2104-11.

12. Dal Poz MR, Kinfu Y, Dräger S, Kunjumen TJWHO. Counting health workers: definitions, data, methods and global results. 2007.

13. Organization WH. The Kampala declaration and agenda for global action. 2008.

14. Organization WH. Report of the First Meeting of the Health Workforce Information Reference Group, Montreux, Switzerland, 10-12 March 2010. World Health Organization; 2010.

15. Organization WH. Global strategy on human resources for health: workforce 2030 2019. Report No.: 9241511133.

16. Organization WH. SEVENTY-SECOND WORLD HEALTH ASSEMBLY Provisional agenda item 12.3: Human resources for health, Global strategy on human resources for health: workforce 2030, Report by the Director-General 2019.

17. Organization WH. Dublin declaration on human resources for health: building the health workforce of the future. 2017.

18. pdf WHOJO. Outcome Statement of the Second Global Forum on Human Resources for Health URL: http://www. who. int/workforcealliance/forum/2011. 2011. 
19. Organization WHOJGWH. WHO global code of practice on the international recruitment of health personnel. 2010.

20. Khan MAH, Azad AK, de Oliveira Cruz VJWS-EAjoph. Bangladesh's digital health journey: reflections on a decade of quiet revolution. 2019;8(2):71-6.

21. Gagnon M-P, Desmartis M, Labrecque M, Car J, Pagliari C, Pluye P, et al. Systematic review of factors influencing the adoption of information and communication technologies by healthcare professionals. 2012;36(1):241-77.

22. Anwar F, Shamim A, Khan SJIJACSA. Barriers in adoption of health information technology in developing societies. 2011;2(8):40-5.

23. Schreier M. Qualitative content analysis in practice: Sage publications; 2012.

24. Administration MoP. Transfer Rules of 3rd and 4th grade employees form one place to another 1986. 1986.

25. Creswell JW, Creswell JD. Research design: Qualitative, quantitative, and mixed methods approaches: Sage publications; 2017.

26. Collins TJPh. Health policy analysis: a simple tool for policy makers. 2005;119(3):192-6.

27. Islam MS, Grönlund Å, editors. Digital Bangladesh-A Change We Can Believe in? International Conference on Electronic Government and the Information Systems Perspective; 2011: Springer.

28. Health Economics Unit M. Health care Financing strategy. MOHFW; 2012-2032.

29. Technology MMoSaIC. National ICT policy. 2009.

30. (MOHFW) MoHaFW. The National Healgth Policy. In: MOHFW, editor.: MOHFW; 2011.

31. (MOHFW) MoHaFWB. Project Implementation Plan (PIP) 2011-16. MOHFW; 2011.

32. Welfare MoHaF. Bangladesh Health Workforce Strategy 2015. 2015.

33. (MOHFW) MoHaFW. Project Implementation Plan (PIP) 2017-22. MOHFW; 2017.

34. (MOHFW) MoHaFW. Inter-Departmental Transfer Policy for BCS (Health) Cadre / Service 9th to 7th Grade and Non-Cadre Officers. 2017.

35. Jimenez-Marroquin MC, Deber R, Jadad ARJRPdSP. Information and communication technology (ICT) and eHealth policy in Latin America and the Caribbean: a review of national policies and assessment of socioeconomic context. 2014;35:329-36.

36. Khoja S, Durrani H, Nayani P, Fahim AJJomlr. Scope of policy issues in eHealth: results from a structured literature review. 2012;14(1):e34.

37. Hoque MR, Mazmum MFA, Bao YJTITMR. e-Health in Bangladesh: current status, challenges, and future direction. 2014;4(2):87-96.

38. Organization WH. Global diffusion of eHealth: making universal health coverage achievable: report of the third global survey on eHealth: World Health Organization; 2017.

39. Waters KP, Mazivila ME, Dgedge M, Necochea E, Manharlal D, Zuber A, et al. eSIP-Saúde: Mozambique's novel approach for a sustainable human resources for health information system. 2016;14(1):1-10. 
40. Kumar R, Shaikh BT, Ahmed J, Khan Z, Mursalin S, Memon MI, et al. The human resource information system: a rapid appraisal of Pakistan's capacity to employ the tool. 2013;13(1):104.

41. Ishijima H, Mapunda M, Mndeme M, Sukums F, Mlay VSJHrfh. Challenges and opportunities for effective adoption of HRH information systems in developing countries: national rollout of HRHIS and TIIS in Tanzania. 2015;13(1):1-14.

42. Ahsan KZ, Streatfield PK, ljdi R-E-, Escudero GM, Khan AW, Reza MJHp, et al. Fifteen years of sectorwide approach (SWAp) in Bangladesh health sector: an assessment of progress. 2016;31(5):612-23.

43. Begum T, Khan SM, Ferdous J, Parvez MM, Rahman A, Kumkum FA, et al. Using DHIS 2 Software to Collect Health Data in Bangladesh. 2019.

44. Waters KP, Zuber A, Willy RM, Kiriinya RN, Waudo AN, Oluoch T, et al. Kenya's health workforce information system: a model of impact on strategic human resources policy, planning and management. 2013;82(9):895-902.

45. Berman P, Bossert TJW, UNAID. A decade of health sector reform in developing countries: what have we learned. 2000.

46. Han WJJophr. Health care system reforms in developing countries. 2012;1(3):199.

47. Biswas T, Pervin S, Tanim MIA, Niessen L, Islam AJBPH. Bangladesh policy on prevention and control of non-communicable diseases: a policy analysis. 2017;17(1):582.

48. Pritchett L, Woolcock M, Andrews MJCfGDWP. Capability traps? The mechanisms of persistent implementation failure. 2010(234).

49. Browne J, Coffey B, Cook K, Meiklejohn S, Palermo CJHpi. A guide to policy analysis as a research method. 2019;34(5):1032-44. 